\title{
Predictors of breastfeeding cessation among HIV- infected women in Dar es Salaam, Tanzania
}

\section{Citation}

Petraro, Paul, Christopher Duggan, Gernard Msamanga, Karen E. Peterson, Donna Spiegelman, and Wafaie Fawzi. 2010. "Predictors of Breastfeeding Cessation Among HIV-Infected Women in Dar Es Salaam, Tanzania." Maternal \& Child Nutrition 7 (3) (January 26): 273-283. doi:10.1111/ j.1740-8709.2009.00236.x.

\section{Published Version}

doi:10.1111/j.1740-8709.2009.00236.x

\section{Permanent link}

http://nrs.harvard.edu/urn-3:HUL.InstRepos:27001569

\section{Terms of Use}

This article was downloaded from Harvard University's DASH repository, and is made available under the terms and conditions applicable to Other Posted Material, as set forth at http:// nrs.harvard.edu/urn-3:HUL.InstRepos:dash.current.terms-of-use\#LAA

\section{Share Your Story}

The Harvard community has made this article openly available.

Please share how this access benefits you. Submit a story.

\section{Accessibility}




\title{
Predictors of breastfeeding cessation among HIV-infected women in Dar es Salaam,Tanzania
}

\author{
Paul Petraro*, Christopher Duggan*, Gernard Msamanga ${ }^{\dagger}$, Karen E. Peterson ${ }^{\star}$, Donna \\ Spiegelman $\neq, \S$, and Wafaie Fawzi ${ }^{*}, \ddagger$ \\ "Department of Nutrition, Harvard School of Public Health, Boston, Massachusetts, USA \\ ‡Department of Epidemiology, Harvard School of Public Health, Boston, Massachusetts, USA \\ $\S$ Department of Biostatistics, Harvard School of Public Health, Boston, Massachusetts, USA \\ tDepartment of Community Health, Muhimbili University College of Health Sciences, Dar es \\ Salaam, Tanzania
}

\begin{abstract}
This paper examines predictors of breastfeeding cessation among a cohort of human immunodeficiency virus (HIV)-infected women. This was a prospective follow-up study of HIVinfected women who participated in a randomized micronutrient supplementation trial conducted in Dar es Salaam, Tanzania. 795 HIV-infected Tanzanian women with singleton newborns were utilized from the cohort for this analysis. The proportion of women breastfeeding declined from $95 \%$ at 12 months to $11 \%$ at 24 months. The multivariate analysis showed breastfeeding cessation was significantly associated with increasing calendar year of delivery from 1995 to 1997 [risk ratio (RR), 1.36; 95\% confidence interval (CI) 1.13-1.63], having a new pregnancy (RR 1.33; 95\% CI 1.10-1.61), overweight [body mass index (BMI) $225 \mathrm{~kg} \mathrm{~m}^{-2}$; RR 1.37; 95\% CI 1.071.75], underweight (BMI <18.5 $\mathrm{kg} \mathrm{m}^{-2}$; RR 1.29; 95\% CI 1.00-1.65), introduction of cow's milk at infant's age of 4 months (RR 1.30; 95\% CI 1.04-1.63). Material and social support was associated with decreased likelihood of cessation (RR 0.83; 95\% CI 0.68-1.02). Demographic, health and nutritional factors among women and infants are associated with decisions by HIVinfected women to cease breastfeeding. The impact of breastfeeding counselling programs for HIV-infected African women should consider individual maternal, social and health contexts.
\end{abstract}

\section{Keywords}

cessation; breastfeeding; HIV; pregnancy; social support

\section{Introduction}

Sixty-eight per cent of human immunodeficiency virus (HIV)-infected persons are in subSaharan Africa and 61\% of those infected with HIV are women (UNAIDS 2007). Breastfeeding is an important source of mother-to-child HIV transmission. In countries where breastfeeding continues into the second year, $30-50 \%$ of all HIV mother-to-child transmission is estimated to occur through this route (De Cock et al. 2000; Dabis \& Ekpini 
2002; Mmiro et al. 2009). Breastfeeding has been recommended by the World Health Organization (WHO) and the United Nations Children's Fund (UNICEF) as the exclusive source of nutrition for infants during the first 6 months of life (WHO/UNICEF/UNAIDS 1998). Expert panels at the time of this trial recommended that HIV-infected women avoid breastfeeding for prevention of mother-to-child transmission if replacement feeding were acceptable, feasible, affordable, sustainable and safe (AFASS) in 2000 and updated the guidelines in 2006 to include exclusive breastfeeding for the first 4-6 months (WHO 2000, 2006). According to the guidelines, HIV-infected mothers should be counselled on the benefits of breastfeeding and the risks of HIV transmission through breast milk and offered other infant feeding options whether it be exclusive breastfeeding or exclusive formula feeding (WHO/UNICEF/UNAIDS 1998). Nevertheless, breastfeeding remains the norm for infant feeding in sub-Saharan Africa (De Cock et al. 2000; Dabis \& Ekpini 2002), including Tanzania.

Recent papers highlight difficulties in implementing infant feeding recommendations for HIV-infected women in sub-Saharan Africa (Bland et al. 2007; Doherty et al. 2007; Lunney et al. 2008), because of unavailability of appropriate alternatives that would potentially increase HIV disease-free survival (Iliff et al. 2005). In Tanzania, feasibility studies of AFASS recommendations have examined infant feeding practices and alternatives to breastfeeding (Manuela de Paoli et al. 2004; Leshabari et al. 2007) and concluded that more work needs to be done in the context of breastfeeding cessation and appropriate alternatives in order to implement these practices.

Several studies have examined predictors of duration of breastfeeding both in developing and developed countries including cross-sectional and observational studies from developed countries, including the United States, Australia and New Zealand, reported longer duration of breastfeeding to be associated with high level of education, child sharing the mother's bedroom, high number of prenatal visits, experience with breastfeeding, younger maternal age and mother receiving support from other sources apart from the clinic (Vogel et al. 1999; Scott et al. 2006). Cross-sectional studies from developing countries, including Tanzania, Thailand and Mexico, have found associations between cessation of breastfeeding and younger maternal age, higher maternal education, maternal employment, and single maternal marital status (Vega Lopez \& Gonzalez Perez 1993; Demographic \& Health Survey 1996; Yimyam \& Morrow 1999). More recent studies in the developing world have looked at infant feeding practices in the general population (Engebretsen et al. 2007; Marriott et al. 2007). These studies showed that early cessation of breastfeeding were associated with high maternal education level, presence of a new pregnancy and illness of the mother or of the child. However, most of these studies were done in settings where the HIV epidemic was not a major public health problem, or did not report on the HIV status of the subjects studied. The effect of maternal HIV infection on breastfeeding cessation has not been well examined.

In the Tanzanian Demographic and Health survey of 1996, about $97 \%$ of children under the age of 5 years whose HIV status was not measured were breastfed during the 12 months before the survey (Demographic \& Health Survey 1996). Identifying predictors of breastfeeding cessation among HIV-infected women is important for targeting the education and counselling message to groups of women at risk for longer breastfeeding. Mmiro et al. suggests that in this setting, women generally breast feed up to 2 years (Mmiro et al. 2009). The importance of improving breastfeeding education programs can lead to increased HIVfree survival as seen in Zimbabwe with exclusive breastfeeding (Iliff et al. 2005). Relatively few studies have examined social support in relation to breastfeeding cessation among HIVinfected women. We examined the association between breastfeeding cessation and 
sociodemographic and health characteristics, as well as social support, over a 24 month period in a cohort of HIV-positive women.

\section{Methods}

\section{Study design and population}

We prospectively followed 1078 HIV-infected women who were participants in a randomized placebo-controlled trial of multivitamins in Dar es Salaam, Tanzania. Details about the study have been described elsewhere (Fawzi et al. 1998). Women between 12 and 27 weeks of gestation were enrolled in the trial from April, 1995 to July, 1997. Study participants received a daily oral dose of one of the following regimens during and after pregnancy: multivitamins, vitamin A alone, multivitamins excluding vitamin $\mathrm{A}$, or placebo. The study was conducted before the implementation of anti-retroviral programs and thus no women received anti-retroviral therapy.

Information on maternal characteristics was collected at baseline and during follow-up. Trained research assistants administered questionnaires on maternal and paternal sociodemographic factors at baseline such as age, education and occupation. Additional data on maternal socio-demographic factors include household expenditure on food and marital status. We collected baseline and follow-up information on maternal reproductive factors, including gestational age at randomization, type of delivery, total number of previous pregnancies as reported by women (parity), outcomes of previous pregnancies (such as low birthweight, preterm delivery, stillbirth and abortion) and occurrence of a second pregnancy while on the study.

Perceived level of social support was measured at 3 months after enrolment, 2 months after delivery and every 6 months thereafter using the Duke functional social support questions (Broadhead et al. 1988). The social support questions have been validated in this study population (Kaaya et al. 2002).

Maternal anthropometry including weight, height, length and mid-upper arm circumference (MUAC) were collected at baseline. These measurements were taken from both mothers and children during monthly follow-up visits using the WHO standardized method (WHO 1995). Clinical data collected at baseline and during follow-up was used to assign maternal HIV disease stage (physician assessment and laboratory values) based on the WHO Staging System (1993).

Child characteristics including gender, anthropometry (weight, length, MUAC and head circumference) and HIV-related factors were recorded at birth and during follow-up. We assessed the presence of diarrhoea and respiratory infection on the day of study visit or in the past month to indicate child morbidity status for each monthly visit. Data on the child feeding patterns such as age when complementary foods in addition to breast milk were introduced and age at introduction of cow's milk/milk powder, porridge, fruits/fruit juice, or solids, and age at cessation of breastfeeding, were recorded at each monthly visit.

Trained research personnel counselled women on the benefits and risks associated with breastfeeding and various options for infant feeding according to the then current WHO and Tanzanian Ministry of Health guidelines. These guidelines were updated in 2000 and an additional consensus statement was released in 2006 based on new evidence that exclusive breastfeeding for the first 4-6 months as being ideal (WHO/UNICEF/UNAIDS 1998; WHO 2000, 2006). Counselling on breastfeeding and general HIV practices was done at recruitment, enrolment and during follow-up on an individual basis as needed. All decisions about whether and how long to breastfeed were made by the mothers. 
Blood specimens were taken for complete blood count including haemoglobin concentration, total lymphocyte count, erythrocyte sedimentation rate and absolute counts of T-cells (CD4+ and CD8+). Specimens were collected at baseline, 6 weeks postpartum and every 6 months thereafter. In a random subset of women, we measured viral loads at baseline and at two other time points after delivery. HIV status of each child was ascertained at birth, 6 weeks and every 3 months thereafter. A child was considered infected when a peripheral blood mononuclear cell specimen tested positive by polymerized chain reaction techniques at any point, or a plasma specimen obtained at 18 or more months of age tested positive by ELISA and confirmed by a Western blot test. A child was considered to be uninfected if either of these two tests were negative at the last visit.

\section{Data analyses}

There were 1078 HIV-infected pregnant women who were randomized in the study; 963 women gave birth to 985 live born babies (i.e. 939 singletons, 21 pairs of twins and 4 pairs of twins with only one alive). Fortyseven children died prior to the first follow-up visit, two mothers died prior to the first follow-up visit, and the remaining 95 have no additional data other than a live delivery. Overall, 811 women reported having ever breastfed their 826 children including 795 women who had singleton live births on whom this analysis is based. Of the 795, the proportion of women who came to the clinic at least once by 3,6 and 12 months after delivery were 91,93 and $95 \%$, respectively. However, 2.3 and $1.5 \%$ of women had their first clinic visit after delivery at 12 and 24 months, respectively, and $9(1.1 \%)$ women never came to clinic after delivery. In the latter cases, the father brought the child to the clinic and breastfeeding status was assessed. The maximum follow-up after delivery was 32 months.

Predictors of breastfeeding cessation examined included paternal age, maternal sociodemographic characteristics, maternal reproductive, nutritional status, HIV-related characteristics [HIV disease stage - clinical staging was used with CD4 counts when available and are shown to be correlated (Edathodu et al. 2009), CD4+], and the child's morbidity history. Maternal social support at baseline was examined overall and by domain, e.g. emotional/affective support and material/instrumental support. Scores were dichotomized as 'have support' ('as much as I would like') and 'not having support' ('never', 'much less' and 'less than I would like'). Child characteristics examined include birthweight and hospitalizations. Maternal body mass index (BMI) was computed from measurements of weight in kilograms divided by the squared height in meters $\left(\mathrm{kg} \mathrm{m}^{-2}\right)$ at all clinic visits. Calendar year of delivery was also recorded and considered as a predictor.

Maternal and child characteristics that could change over time were also analyzed as timevarying covariates. The maternal time-varying characteristics were HIV disease stage, CD4+ cell count, BMI and child hospitalizations in the last month considered as time dependent. Time-dependent characteristics were updated until the month when cessation of breastfeeding occurred or an observation was censored. For women who had a new pregnancy while in the study, maternal characteristics such as weight were updated until the first day of conception computed from last normal menstrual period or gestational age at delivery. The latter excludes all weights during subsequent pregnancies to avoid spurious BMI calculations as a time-dependent variable. Maternal blood parameters for all women $(\mathrm{CD} 4+, \mathrm{CD} 8+$,$) were updated every 6$ months. If a woman missed a visit and had a blood specimen beyond 6 months, values were considered as missing until the next available results were obtained and there was an update. Continuous and categorical predictors are presented using conventional or known cutoffs from values that were previously reported in this study using the median or upper 25th percentile from the study population, or according to WHO standard cut-off for BMI (1995). 
Cessation of breastfeeding was defined using a twostep algorithm. First, the duration of breastfeeding was estimated as the average of the latest age at which the child was reported to be breastfeeding and the earliest age at which the child was reported as not breastfeeding for at least two consecutive monthly assessments ( $n=593$ children). If the child missed a clinic visit and there was a period longer than 42 days between these two visits ( $n=202$ children), we used the age the mother reported she had stopped breastfeeding. Because we were interested in women's decision to stop breastfeeding, cessation was considered to have occurred only if the woman was still breastfeeding at the prior visit to the one at which cessation was reported to have occurred, and neither the woman nor child died within a month of that time. Voluntary cessation of breastfeeding is defined as survival of both mother and child at least 1 month beyond the computed time of breastfeeding cessation (or last time known to be breastfeeding), with both having visited study clinics at least once past that time. Henceforth, we will refer to women meeting these criteria as voluntary stoppers, and to the event as voluntary cessation of breastfeeding. Time to voluntary cessation of breastfeeding was analyzed using survival analysis methods. We used the Kaplan-Meier (KM) method to estimate the median duration of breastfeeding and the proportion of women who were breastfeeding at each time after delivery (Kaplan \& Meier 1958).

Cox-proportional hazards regression methods were used to examine predictors of voluntary breastfeeding cessation for both univariate and multivariate analyses and to calculate $95 \%$

CI (Cox 1972). The Wald test statistic was used to assess the significance of the association between continuous or categorical variables, and the time to voluntary cessation of breastfeeding. Predictors with a univariate $P$-value of 0.20 or less were introduced into the multivariate model, using sas/stat, version 9.1, statistical software from SAS Institute Inc. (Cary, NC, USA). In the multivariate model, we used the counting process data structure to incorporate time-dependent covariates, i.e. predictors that were changing or updated over time (Andersen \& Gill 1982). The time interval corresponded to the monthly follow-up visits after delivery. In order to avoid the problem of retaining one level of a categorical variable in the final model as selected by automated stepwise model procedure, the model was developed manually in multiple stages using the likelihood ratio test.Variables were retained in the final model if the overall $P$-value was 0.10 or less. We forced into the final model variables that were not significant on univariate analyses but important in HIV infection (disease stage, $\mathrm{CD} 4+$ ) and those known a priori to predict breastfeeding cessation, including maternal age. Observations with missing data were retained in the analyses by using missing indicators. To check for bias in the missing indicators, only cases with no missing results were input into the model and compared to our final model with missing indicators and the results were substantially the same (no measure changed by more than $10 \%)$. We used Cox proportional hazards regression with stepwise selection of restricted cubic splines to obtain effect estimates and test for non-linearity between continuous predictors and time to voluntary cessation of breastfeeding (Durrleman \& Simon 1989).

The Research and Publications Committee of Muhimbili University College of Health Sciences, the ethical Committee of the National AIDS Control program of the Tanzanian Ministry of Health and the Institutional Review Board of the Harvard School of Public Health approved the study protocol.

\section{Results}

Breastfeeding was initially adopted by almost all women. The estimated KM proportions of women $(n=795)$ who were breastfeeding at 9,12, 18 and 24 months were 97, 95, 72 and $11 \%$, respectively. The mean duration of breastfeeding among voluntary stoppers was 20.2 months [95\% confidence interval (CI), 20.0-21.0 months]. The minimum and maximum duration of breastfeeding were 0.1 and 32.0 months, respectively. Overall, 524 (66\%) 
women reported voluntary breastfeeding cessation (non-censored events). Timing of breastfeeding cessation is shown in Fig. 1 where the cumulative incidence of cessation is reported for the 524 women who reported voluntary breastfeeding cessation. Of the remaining 271 women (34\%), 147 were censored for the death of the child and 16 were censored for death of the mother.

The percentages of those who voluntarily stopped breastfeeding are presented in Table 1 . The average age of women in the study was 25 years, with the majority (78\%) having 5-8 years of education and 58\% being in monogamous relationships (Table 1). The average gestational ages at randomization and delivery were 20 and 39 weeks respectively. The majority (92\%) of women had a spontaneous normal delivery, and $34 \%$ went on to have a second pregnancy while in the study. At baseline, $85 \%$ of women were HIV disease stage I according to WHO Staging System assessed by clinical assessment and laboratory values from CD4 counts (Edathodu et al. 2009), 29\% had a CD4+ count of 500 or more. At 6 weeks postdelivery, $61 \%$ of women were in the normal range for BMI (18.5 to $24.9 \mathrm{~kg} \mathrm{~m}^{-2}$ ) (1995). The average birthweight of infants was $3052 \mathrm{~g}$, with gender evenly distributed. The reported average age at introduction of other foods was as follows: porridge (4.3 months), fruits (5.7 months), cow milk/milk powder (7.6 months) and solid foods ( 8.5 months).

The univariate and multivariate analyses for breastfeeding cessation are presented in Table 2. Using the Cox proportional hazards models to adjust for other significant predictors, each additional calendar year of delivery was a significant predictor of earlier breastfeeding cessation [relative risk of breastfeeding cessation (RR) 1.36 ; 95\% CI 1.13-1.63; $P$-value $=$ $0.001]$. Women who went on to have a new pregnancy were also significantly more likely to stop breastfeeding (RR $1.33 ; 95 \%$ CI $1.10-1.61 ; P$-value $=0.004)$. High maternal postdelivery BMI ( $\geq 25 \mathrm{~kg} \mathrm{~m}^{-2}$ ) was a significant predictor of early breastfeeding cessation, compared to women who were in the BMI range of $18.5-25 \mathrm{~kg} \mathrm{~m}^{-2}$ (RR 1.37; 95\% CI 1.07$1.75 ; P$-value $=0.01)$. As expected, women who introduced cows milk $/$ milk powder to their infants at or before age 4 months were significantly more likely to have earlier cessation of breastfeeding (RR 1.30; 95\% CI 1.04-1.63; $P$-value $=0.02$ ) compared with those who introduced cow's milk/milk powder to their children after 4 months of age. After adjusting for other significant predictors of breastfeeding cessation, women were $13 \%$ less likely to have earlier breastfeeding cessation for every 5 -year increase in age (RR 0.87; 95\% CI 0.79$0.96 ; P$-value $=0.007)$. Women who reported one or more spontaneous abortions in the past were $20 \%$ less likely to stop breastfeeding earlier compared with those who did not have any abortions (RR 0.80; 95\% CI 0.65-0.98; $P$-value $=0.03)$. Instrumental and material support was significant in the univariate analysis (RR $0.76 ; 95 \%$ CI $0.63-0.91 ; P$-value $=0.004)$ and when adjusting for other predictors using the Cox proportional hazards model was consistent with the univariate although insignificant at an alpha level of 0.05 (RR 0.83 ; 95\% CI 0.68$1.02 ; P$-value $=0.07)($ Table 2$)$.

\section{Discussion}

Most studies on risk factors for early breastfeeding cessation have been conducted among women whose HIV status was not determined and were most likely predominantly uninfected due to the low prevalence of HIV (Jakobsen et al. 1996). Little is known about factors associated with breastfeeding cessation among HIV-positive women. We reported predictors of breastfeeding cessation among lactating HIV-infected women in Tanzania. The median time of breastfeeding in our study was 20.2 months, approximately similar to the Tanzanian national demographic and health surveys in 1996 where the median time was 22 months (Demographic \& Health Survey 1996). Characteristics related to earlier breastfeeding cessation in our study were year of delivery, having a new pregnancy, high post delivery BMI of $\geq 25 \mathrm{~kg} \mathrm{~m}^{-2}$ and early introduction of cow milk below 4 months of age. 
The higher rate of earlier cessation of breastfeeding with later calendar year was probably due to the availability of new research findings on the risks associated with prolonged breastfeeding. At the time of enrolment (between 1995 and 1997), there was limited information on how best to counsel HIV-infected women on the risks associated with breastfeeding. While conducting the trial, the 1998 report by WHO on breastfeeding guidelines based on data supporting AFASS and early cessation as the preferable options (WHO/UNICEF/UNAIDS 1998) leading to early rates of cessation.

Having a new pregnancy was associated with earlier cessation of breastfeeding in our study. Similar findings were observed in previous studies from developing countries (Forman 1984; Jakobsen et al. 1996). High post-delivery BMI was also associated with earlier weaning. However, studies from Australia and United States showed that women with high prepregnancy weight and who gained weight beyond the recommended level during pregnancy and lactation period were less likely both to initiate breastfeeding and to stop breastfeeding early (Rutishauser \& Carlin 1992; Li et al. 2003). This phenomenon may be explained by a finding that overweight women in the United States had lower prolactin response to suckling and possibly failure in lactation during the early post-partum period (Rasmussen \& Kjolhede 2004).

Early introduction of cow's milk or powdered milk was associated with earlier cessation of breastfeeding in our study. Previous studies have shown an association between early introduction of infant formula and cessation of breastfeeding both in developed and developing countries (Vogel et al. 1999; Hornell et al. 2001; Berra et al. 2003).

Support was divided into two categories: instrumental and material support was support in fulfilling daily activities whether it is monetary or actively helping such as domestic chores and transportation; compared with emotional and affective support which is through social support systems such as family and friends advising the women. Instrumental and material support (which included help with domestic chores, monetary assistance, transportation, etc.) was associated with delayed cessation of breastfeeding. A recent study from Nigeria showed having additional female support in the postpartum period to be beneficial to breastfeeding for 4-6 months (Olayemi et al. 2007). Another study in Zimbabwe showed that when an educational program was implemented for safer breastfeeding practices, $79 \%$ were less likely to expose their child to HIV infection (Piwoz et al. 2007). Although the majority of our findings led to increased cessation of breastfeeding, in our setting where the support structure tends to be stronger, we saw that outside assistance was associated with continued breastfeeding in our study population. We found that emotional and affective support, however, was not related with breastfeeding cessation. These findings point to the importance of measuring and understanding the role of different types of social support in this cultural context, particularly in relation to management of breastfeeding in HIV-infected women.

Some recommend that recall of exclusive breastfeeding should be done on a weekly basis to minimize recall bias (Bland et al. 2003). Our data define the duration of breastfeeding to be where the mothers reported nothing more than breastfeeding at the latest age in the previous month and earliest time of not breastfeeding and took the average. Based on this algorithm and due to the fact that there are repeated measures over an extended period of time, it is expected to minimize the recall bias. This study provided a unique opportunity to examine the associations of breastfeeding in a large sample of HIV-positive women in the developing world where improved breastfeeding strategies can be one of the most effective ways to improve infant and childhood morbidity and mortality. Demographic, health and nutritional factors among women and infants are associated with decisions by HIV-infected women to cease breastfeeding. The impact of breastfeeding counselling programs for HIV-infected 
African women should consider individual maternal, social and health contexts. The identified factors may be important in updating the counselling messages on breastfeeding HIV-infected women in Tanzania. Counselling strategies should incorporate contextualized protocols, which include information such as the predictors seen in a number of settings (Lauer et al. 2004; Piwoz et al. 2006; Olayemi et al. 2007) including those reported here. It is clear that with the appropriate counselling strategies and social support systems, adherence to guidelines is possible. Counselling on breastfeeding should factor in individual maternal social and health contexts, and child feeding pattern and health status in prenatal and post-natal clinics. In a 2006 consensus statement by the WHO, the 2001 guidelines on breastfeeding (WHO/UNICEF/UNAIDS 1998) were updated to include exclusive breastfeeding for the first 6 months may be appropriate if AFASS is not met or it is not appropriate to stop. (2006) One factor is the difficulty in providing an adequate diet at this age (Dewey et al. 2004). If mothers are to adhere to the guidelines they will need adequate counselling and social support, and policy makers need an understanding of the context in which such decisions are made, and the determinants associated with these decisions.

\section{Acknowledgments}

We thank the women who made the study possible through their participation. We thank the clinic coordinators, research assistants, laboratory technicians, nurses, midwives and administrative staff in the field. We thank Dr Anna Marie Kiure for all her work in the initial stages of this project.

Source of funding This work was supported in part by the National Institute of Child Health and Human Development (NICHD R01 32257).

\section{References}

Andersen PK, Gill RD. Cox's regression model for counting processes: a large sample study. Annals of Statistics. 1982; 10:1100-1120.

Berra S, Sabulsky J, Rajmil L, Passamonte R, Pronsato J, Butinof M. Correlates of breastfeeding duration in an urban cohort from Argentina. Acta Paediatrica. 2003; 92:952-957. [PubMed: 12948072]

Bland RM, Rollins NC, Solarsh G, Van Den Broeck J, Coovadia HM. Maternal recall of exclusive breast feeding duration. Archives of Disease in Childhood. 2003; 88:778-783. [PubMed: 12937095]

Bland RM, Rollins NC, Coovadia HM, Coutsoudis A, Newell ML. Infant feeding counselling for HIVinfected and uninfected women: appropriateness of choice and practice. Bulletin of the World Health Organization. 2007; 85:289-296. [PubMed: 17546310]

Broadhead WE, Gehlbach SH, De Gruy FV, Kaplan BH. The Duke-UNC Functional Social Support Questionnaire. Measurement of social support in family medicine patients. Medicine Care. 1988; 26:709-723.

Cox DR. Regression models and life tables. Journal of the Royal Statistical Society. Series B. 1972; 34:187-220.

Dabis F, Ekpini ER. HIV-1/AIDS and maternal and child health in Africa. Lancet. 2002; 359:20972104. [PubMed: 12086778]

De Cock KM, Fowler MG, Mercier E, De Vincenzi I, Saba J, Hoff E, et al. Prevention of mother-tochild HIV transmission in resource-poor countries: translating research into policy and practice. JAMA. 2000; 283:1175-1182. [PubMed: 10703780]

Dewey KG, Cohen RJ, Rollins NC. WHO technical background paper: feeding of nonbreastfed children from 6 to 24 months of age in developing countries. Food and Nutrition Bulletin. 2004; 25:377-402. [PubMed: 15646315]

Doherty T, Chopra M, Jackson D, Goga A, Colvin M, Persson LA. Effectiveness of the WHO/ UNICEF guidelines on infant feeding for HIV-positive women: results from a prospective cohort study in South Africa. Aids. 2007; 21:1791-1797. [PubMed: 17690578]

Durrleman S, Simon R. Flexible regression models with cubic splines. Statistics in Medicine. 1989; 8:551-561. [PubMed: 2657958] 
Edathodu J, Ali B, Alrajhi AA. CD4 validation for the World Health Organization classification and clinical staging of HIV/AIDS in a developing country. International Journal of Infectious Diseases. 2009; 13:243-246. [PubMed: 18945632]

Engebretsen IM, Wamani H, Karamagi C, Semiyaga N, Tumwine J, Tylleskar T. Low adherence to exclusive breastfeeding in Eastern Uganda: a community-based cross-sectional study comparing dietary recall since birth with 24-hour recall. BMC Pediatrics. 2007; 7:10. [PubMed: 17331251]

Fawzi WW, Msamanga GI, Spiegelman D, Urassa EJ, Mcgrath N, Mwakagile D, et al. Randomised trial of effects of vitamin supplements on pregnancy outcomes and T cell counts in HIV-1-infected women in Tanzania. Lancet. 1998; 351:1477-1482. [PubMed: 9605804]

Forman MR. Review of research on the factors associated with choice and duration of infant feeding in less-developed countries. Pediatrics. 1984; 74:667-694. [PubMed: 6384918]

Hornell A, Hofvander Y, Kylberg E. Solids and formula: association with pattern and duration of breastfeeding. Pediatrics. 2001; 107:E38. [PubMed: 11230619]

Iliff PJ, Piwoz EG, Tavengwa NV, Zunguza CD, Marinda ET, Nathoo KJ, et al. Early exclusive breastfeeding reduces the risk of postnatal HIV-1 transmission and increases HIV-free survival. Aids. 2005; 19:699-708. [PubMed: 15821396]

Jakobsen MS, Sodemann M, Molbak K, Aaby P. Reason for termination of breastfeeding and the length of breastfeeding. International Journal of Epidemiology. 1996; 25:115-121. [PubMed: 8666478]

Kaaya SF, Fawzi MC, Mbwambo JK, Lee B, Msamanga GI, Fawzi W. Validity of the Hopkins Symptom Checklist-25 amongst HIV-positive pregnant women in Tanzania. Acta Psychiatrica Scandinavica. 2002; 106:9-19. [PubMed: 12100343]

Kaplan EL, Meier P. Nonparametric estimation from incomplete observations. Journal of the American Statistical Association. 1958; 53:457-481.

Lauer JA, Betran AP, Victora CG, De Onis M, Barros AJ. Breastfeeding patterns and exposure to suboptimal breastfeeding among children in developing countries: review and analysis of nationally representative surveys. BMC Medicine. 2004; 2:26. [PubMed: 15230974]

Leshabari SC, Blystad A, Moland KM. Difficult choices: Infant feeding experiences of HIV-positive mothers in northern Tanzania. Sahara Journal. 2007; 4:544-555. [PubMed: 18040533]

Li R, Jewell S, Grummer-Strawn L. Maternal obesity and breastfeeding practices. The American Journal of Clinical Nutrition. 2003; 77:931-936. [PubMed: 12663294]

Lunney KM, Jenkins AL, Tavengwa NV, Majo F, Chidhanguro D, Iliff P, et al. HIV-positive poor women may stop breastfeeding early to protect their infants from HIV infection although available replacement diets are grossly inadequate. The Journal of Nutrition. 2008; 138:351-357. [PubMed: 18203903]

Manuela de Paoli M, Manongi R, Klepp KI. Are infant feeding options that are recommended for mothers with HIV acceptable, feasible, affordable, sustainable and safe? Pregnant women's perspectives. Public Health Nutrition. 2004; 7:611-619. [PubMed: 15251051]

Marriott BM, Campbell L, Hirsch E, Wilson D. Preliminary data from demographic and health surveys on infant feeding in 20 developing countries. The Journal of Nutrition. 2007; 137:518S-523S. [PubMed: 17237339]

Mmiro FA, Aizire J, Mwatha AK, Eshleman SH, Donnell D, Fowler MG, et al. Predictors of early and late mother-to-child transmission of HIV in a breastfeeding population: HIV Network for Prevention Trials 012 experience, Kampala, Uganda. Journal of Acquired Immune Deficiency Syndromes. 2009; 52:32-39. [PubMed: 19617849]

National Bureau Of Statistics Dar Es Salaam T.. United Republic Of Tanzania. Orc Macro Calverton M., USA. Tanzania Demographic and Health Survey (TDHS). Bureau of Statistics [Tanzania] and Macro International; Calverton, Maryland: 1996. p. 123-126.

Olayemi O, Aimakhu CO, Bello FA, Motayo VO, Ogunleye AA, Odunukan OW, et al. The influence of social support on the duration of breast-feeding among antenatal patients in Ibadan. Journal of Obstetrics and Gynaecology. 2007; 27:802-805. [PubMed: 18097898]

Piwoz EG, Ferguson YO, Bentley ME, Corneli AL, Moses A, Nkhoma J, et al. Differences between international recommendations on breastfeeding in the presence of HIV and the attitudes and 
counselling messages of health workers in Lilongwe, Malawi. International Breastfeeding Journal. 2006; 1:2. [PubMed: 16722580]

Piwoz EG, Humphrey JH, Tavengwa NV, Iliff PJ, Marinda ET, Zunguza CD, et al. The impact of safer breastfeeding practices on postnatal HIV-1 transmission in Zimbabwe. American Journal of Public Health. 2007; 97:1249-1254. [PubMed: 17538064]

Rasmussen KM, Kjolhede CL. Prepregnant overweight and obesity diminish the prolactin response to suckling in the first week postpartum. Pediatrics. 2004; 113:e465-e471. [PubMed: 15121990]

Rutishauser IH, Carlin JB. Body mass index and duration of breast feeding: a survival analysis during the first six months of life. Journal of Epidemiology and Community Health. 1992; 46:559-565. [PubMed: 1494068]

Scott JA, Binns CW, Oddy WH, Graham KI. Predictors of breastfeeding duration: evidence from a cohort study. Pediatrics. 2006; 117:e646-e655. [PubMed: 16585281]

UNAIDS. AIDS Epidemic Update. WHO Library; Geneva: 2007.

Vega Lopez MG, Gonzalez Perez GJ. Maternal factors relating to breast-feeding duration in areas around Guadalajara, Mexico. Bulletin of the Pan American Health Organization. 1993; 27:350359. [PubMed: 8312958]

Vogel A, Hutchison BL, Mitchell EA. Factors associated with the duration of breastfeeding. Acta Paediatrica. 1999; 88:1320-1326. [PubMed: 10626515]

WHO. Physical Status: The Use and Interpretation of Anthropometry. World Health Organization; Geneva: 1995. Technical Report Series no. 854Report of a WHO expert Committtee

WHO. New Data on the Prevention of Mother-to-child Transmission of HIV and Their Policy Implications. World Health Organization; Geneva: 2000. Conclusions and Recommendations. Technical Consultation of the United Nations Population Fund (UNFPA)/ United Nations Children's Fund (UNICEF)/WHO/Joint United Nations Programme on HIV/AIDS (UNAIDS) Inter-Agency Task Team on Mother-to-Child Transmission of HIV

WHO. WHO HIV and Infant Feeding Technical Consultation Held on Behalf of the Inter-Agency Task Team (IATT) on Prevention of HIV Infections in Pregnant Women, Mothers and Their Infants. World Health Organization; Geneva: 2006.

WHO Staging System. Proposed 'World Health Organization staging system for HIV infection and disease': preliminary testing by an international collaborative cross-sectional study. The WHO International Collaborating Group for the Study of the WHO Staging System. Aids. 1993; 7:711718. [PubMed: 8100422]

WHO/UNICEF/UNAIDS. HIV and infant feeding guidelines for decision-makers. WHO/UNICEF/ UNAIDS Report. 1998; (2):1-31.

Yimyam S, Morrow M. Breastfeeding practices among employed Thai women in Chiang Mai. Journal of Human Lactation. 1999; 15:225-232. [PubMed: 10578801] 


\section{Key messages}

- The reasons that HIV-infected women elect to discontinue breastfeeding have not been well established in the literature.

- Breastfeeding in HIV-positive populations needs to be better understood to manage counselling strategies of women in this population.

- Understanding predictors of breastfeeding cessation are vital to improving the guidelines and practices of HIV-positive women. 


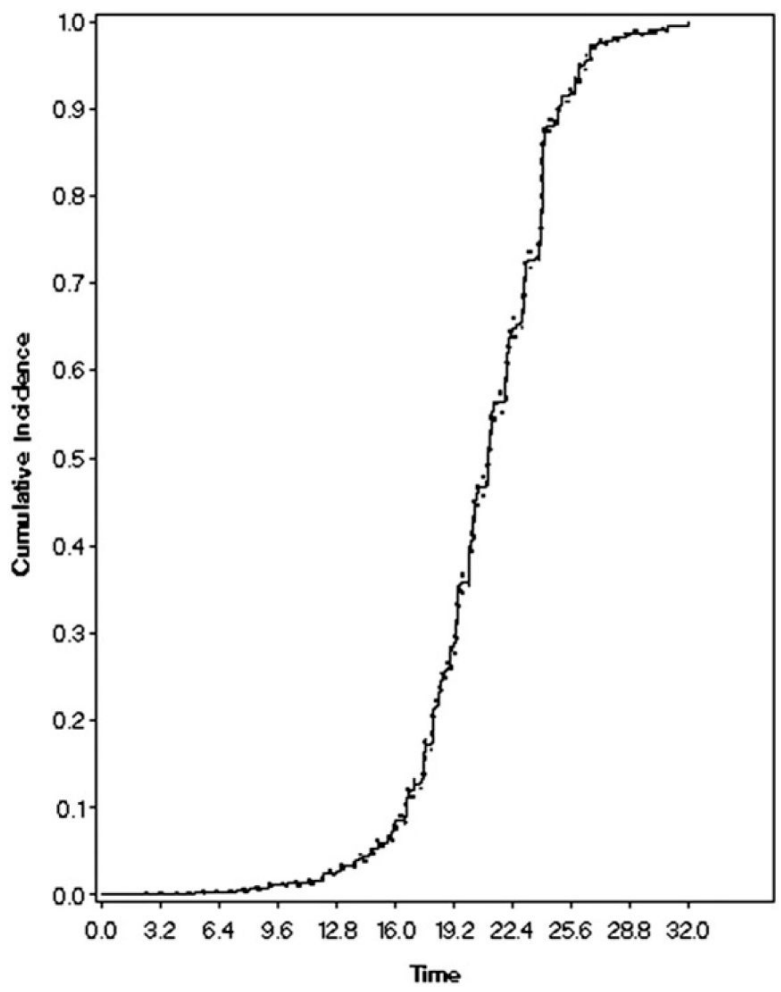

Fig. 1.

Cumulative incidence of women ceasing to breast feed. $N=524$. 
Table 1

Characteristics of the study population at baseline and delivery

\begin{tabular}{|c|c|c|}
\hline Continuous characteristics* & $N^{*}$ & $\operatorname{Mean}(\mathbf{S D}) *$ \\
\hline Maternal age at baseline (years) & 795 & $24.7(4.7)$ \\
\hline Partners' age (years) & 535 & $32.9(6.7)$ \\
\hline $\begin{array}{l}\text { Household expenditure on food per person per } \\
\text { day (TShs) }\end{array}$ & 711 & $527.6(261.9)$ \\
\hline Baseline CD4+ cell counts (per 100 cells) & 749 & $422.8(193.5)$ \\
\hline Baseline viral load (copies/mL) & 352 & $149,083(301,085)$ \\
\hline Categorical characteristics ${ }^{*}$ & & $N(\%)^{*}$ \\
\hline \multicolumn{3}{|l|}{ Maternal age (years) $(n=795)$} \\
\hline$<20$ & & $96(12.1)$ \\
\hline $20-24$ & & $319(40.1)$ \\
\hline $25-29$ & & $250(31.4)$ \\
\hline 230 & & $130(16.4)$ \\
\hline \multicolumn{3}{|l|}{ Weeks gestation at baseline $(n=795)$} \\
\hline$\geq 16$ & & $628(79.0)$ \\
\hline$<16$ & & $167(21.0)$ \\
\hline \multicolumn{3}{|l|}{ Maternal education (years) $(n=795)$} \\
\hline None and adult education & & $55(6.9)$ \\
\hline Primary, $1-4$ years & & $38(4.8)$ \\
\hline Primary, $5-8$ years & & $620(78.0)$ \\
\hline Secondary and university, $\geq 9$ years & & $82(10.3)$ \\
\hline \multicolumn{3}{|l|}{ Maternal occupation $(n=795)$} \\
\hline Housewife & & $579(72.8)$ \\
\hline Professional and employed & & $73(9.2)$ \\
\hline Business, public house, other & & $143(18.0)$ \\
\hline \multicolumn{3}{|l|}{ Marital status $(n=795)$} \\
\hline Married, monogamous & & $461(58.0)$ \\
\hline Married, polygamous & & $47(5.9)$ \\
\hline Single, divorced, widow & & $197(24.8)$ \\
\hline Cohabiting & & $90(11.3)$ \\
\hline \multicolumn{3}{|l|}{ Type of delivery $(n=780)$} \\
\hline SVD & & $731(92.2)$ \\
\hline Others $^{\dagger}$ & & $49(7.8)$ \\
\hline \multicolumn{3}{|l|}{ Material/instrumental support $(n=795)$} \\
\hline No support & & $387(48.7)$ \\
\hline Support & & $408(51.3)$ \\
\hline \multicolumn{3}{|c|}{ Number of previous pregnancies (including abortions) $(n=781)$} \\
\hline None & & $194(24.8)$ \\
\hline 1 & & $221(28.3)$ \\
\hline
\end{tabular}




\begin{tabular}{|c|c|c|}
\hline Continuous characteristics ${ }^{*}$ & $N^{*}$ & $\operatorname{Mean}(\mathbf{S D}) *$ \\
\hline 2 & & $151(19.3)$ \\
\hline$\geq 3(3-12)$ & & $215(27.5)$ \\
\hline \multicolumn{3}{|c|}{ Number of previous abortions $(n=793)$} \\
\hline None & & $591(74.5)$ \\
\hline$>1$ & & $202(25.5)$ \\
\hline \multicolumn{3}{|c|}{ Second pregnancy (while in study) $(n=795)$} \\
\hline No & & $524(65.9)$ \\
\hline Yes & & $271(34.1)$ \\
\hline \multicolumn{3}{|c|}{ Child age at introduction of cow milk/milk powder $(n=608)$} \\
\hline$\geq 4$ & & 475 (75.6) \\
\hline$<4$ & & $153(24.4)$ \\
\hline \multicolumn{3}{|l|}{ Child hospitalizations $(n=731)$} \\
\hline No & & $712(97.4)$ \\
\hline Yes & & $19(2.6)$ \\
\hline \multicolumn{3}{|c|}{ Post-delivery BMI $\left(\mathrm{kg} \mathrm{m}^{-2}\right)(n=795)$} \\
\hline$<18.5$ & & $64(8.1)$ \\
\hline $18.5-24.9$ & & $487(61.3)$ \\
\hline$>25$ & & $244(30.7)$ \\
\hline \multicolumn{3}{|c|}{ Baseline serum vitamin A level $\left(\mu \mathrm{g} \mathrm{dL}^{-1}\right)(n=624)$} \\
\hline$<20$ (deficiency) & & $209(33.5)$ \\
\hline$\geq 20$ (normal level) & & $415(66.5)$ \\
\hline \multicolumn{3}{|c|}{ WHO HIV disease stage $(n=795)$} \\
\hline Stage I & & $679(85.4)$ \\
\hline Stage II & & 108 (13.6) \\
\hline Stage III and IV & & $8(1.0)$ \\
\hline \multicolumn{3}{|l|}{ Birthweight (grams) $(n=720)$} \\
\hline$<2500$ & & $62(8.6)$ \\
\hline$\geq 2500$ & & $658(91.4)$ \\
\hline
\end{tabular}

SD, standard deviation; BMI, body mass index; SVD, standard vaginal delivery

The denominator included only those with non-missing values. Units are TShs = Tanzanian shillings (US dollar is estimated at approximately 600-650 TShs at the time of randomization from 1995 to 1997).

${ }^{\dagger}$ Type of delivery for other category include: elective caesarean section (C/S), emergency C/S, vacuum extraction and assisted breech delivery. Measurements for BMI were done 6 weeks after delivery. There was only one woman who was in HIV disease stage IV at baseline. 


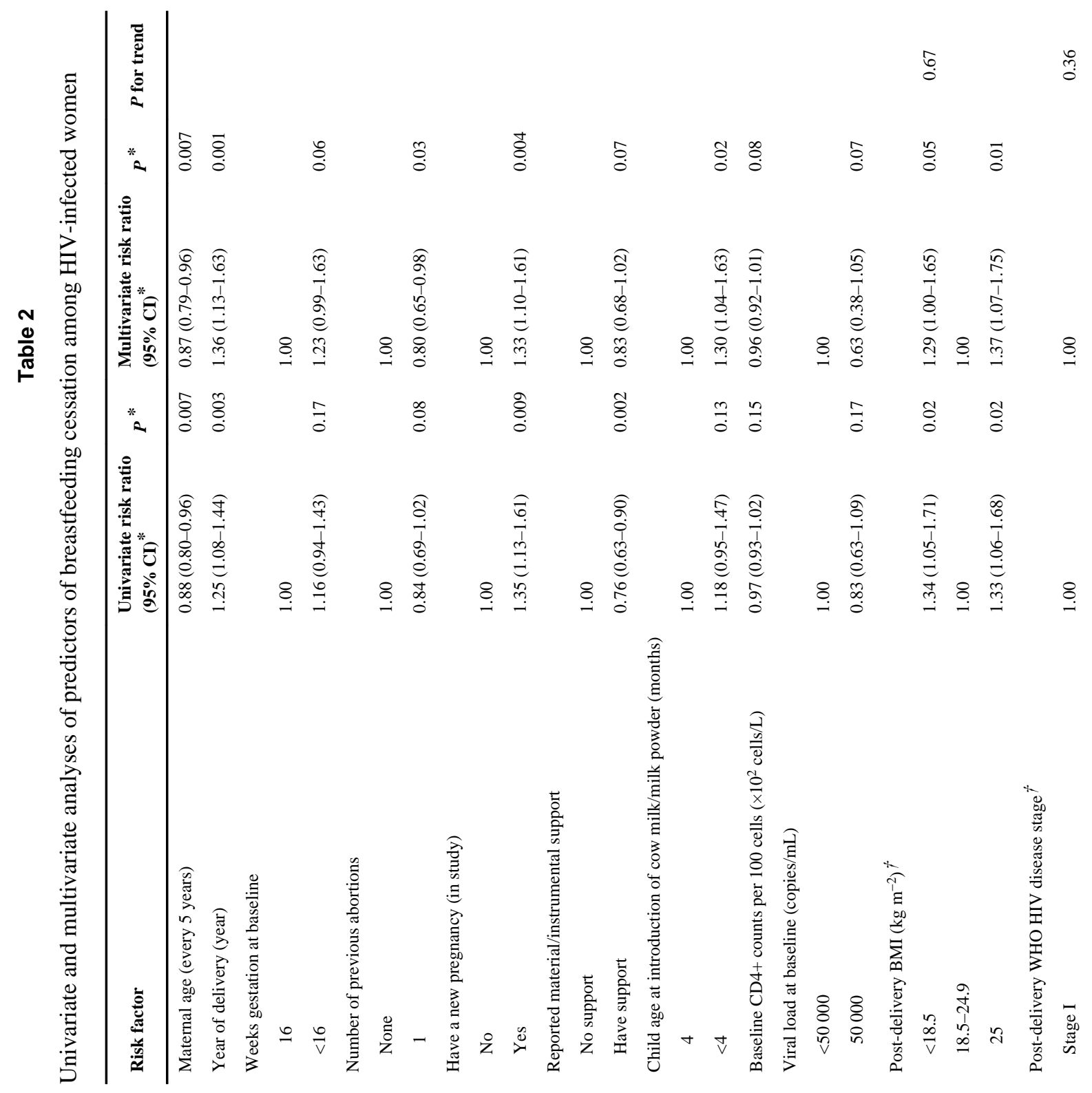




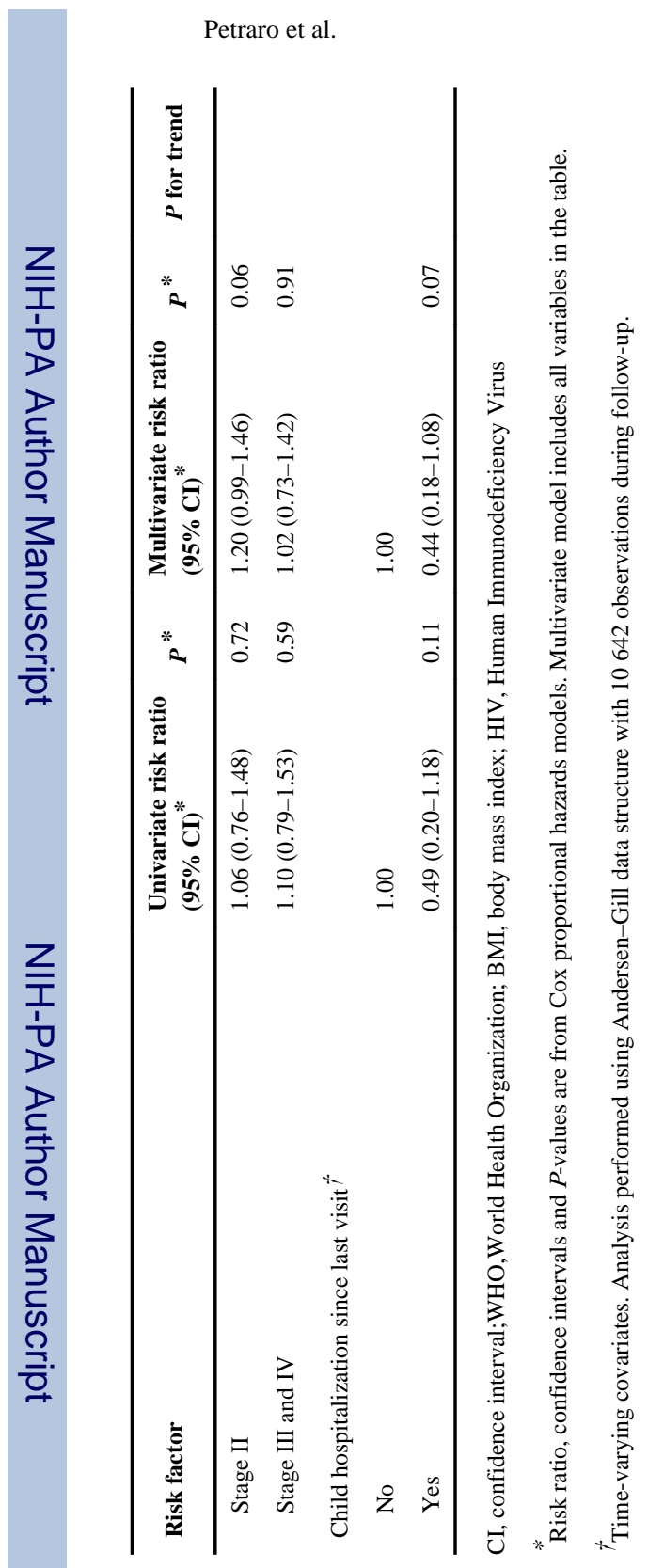

Page 16

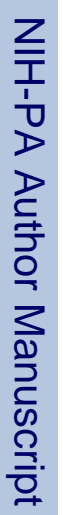

